\title{
Um estudo preliminar sobre a influência de um jogo digital de bocha no desempenho e aprendizagem de estudantes com deficiência
}

\author{
Cristiane S. Ribeiro, Danilo da S. Porfírio, Paulo César dos Santos, Ieda M. S. \\ Kawashita, Aracele G. O. Fassbinder
}

Instituto Federal de Educação, Ciência e Tecnologia do Sul de Minas Gerais - Campus Muzambinho (IFSULDEMINAS) - Muzambinho - MG - Brasil

cris-muzambinho@hotmail.com, daniloporfiriol2@gmail.com, \{paulo.santos, ieda.kawashita, aracele.garcia\}@muz.ifsuldeminas.edu.br

\begin{abstract}
Sports initiation activities can be used as a way to promote learning and people disabilities inclusion. Similarly, practices involving the use of digital technologies may also contribute to the cognitive development of such people. In order to promote interdisciplinarity between Physical Education and Computer Science areas, a project has been conducted in APAE of Muzambinho, $M G$. This paper describes the results of a preliminary case study that investigated the influence of an online bocce game on the performance of participants in paralympic boccia. At the end, there was an improvement in the performance of the participants in court, in almost all cases considered.
\end{abstract}

Resumo. Atividades de iniciação ao esporte podem ser utilizadas como uma forma de promover a aprendizagem e a inclusão de pessoas com deficiência. De forma similar, práticas envolvendo o uso de tecnologias digitais também podem contribuir com desenvolvimento cognitivo dessas pessoas. A fim de promover a interdisciplinaridade entre as áreas de Educação Física e Ciência da Computação, um projeto tem sido conduzido na APAE de Muzambinho, MG. Este artigo descreve os resultados de um estudo de caso preliminar que investigou a influência de um jogo online de bocha sobre a performance dos participantes nas atividades de bocha paralímpica. Ao final, evidenciou-se uma melhoria no desempenho dos participantes em quadra, em quase todos os casos analisados.

\section{Introdução}

A inclusão social de pessoas com deficiência é um tema muito discutido na atualidade. Sobral et al. (2017), por exemplo, destacam a importância dos estudos e pesquisas nessa área e afirmam que embora haja consenso sobre a importância da inclusão, esse conceito ainda não é exercido plenamente. De acordo com a legislação brasileira, foi sancionada em 6 de julho de 2015 a lei $n^{o} 13.146$ (BRASIL, 2015, p. 1), que estabelece no artigo $1^{\circ}$ que se deve "assegurar e promover, em condições de igualdade, o exercício dos direitos e das liberdades fundamentais por pessoa com deficiência, visando a sua inclusão social e cidadania". Assim, a inclusão social de pessoas com deficiência nas escolas, e demais ambientes que promovem atividades desportivas, pode ser desenvolvida com o objetivo de proporcionar conhecimentos que resultem em melhorias na socialização dos indivíduos. No processo de incluir e socializar será possível criar oportunidades iguais para pessoas com deficiência, onde cada um possa desenvolver a capacidade de superar 
VII Congresso Brasileiro de Informática na Educação (CBIE 2018)

Anais do XXIV Workshop de Informática na Escola (WIE 2018)

seus próprios limites.

Segundo Bittar (2013), a prática de exercícios físicos é uma forma preventiva e atrativa de manter e melhorar o estado de saúde física e psíquica, apresentando benefícios para retardar as perdas funcionais ao longo do tempo, além de manter a boa qualidade de vida dos seus praticantes.

No ambiente escolar, práticas desportivas são essenciais para o desenvolvimento de cada aprendiz. Jogos pré-desportivos, por exemplo, constituem-se como uma preparação para indivíduos que desejam iniciar um desporto. Quando inseridos nessas práticas, os estudantes podem desenvolver grande capacidade cognitiva, habilidades sociais e motoras. Isso faz dos jogos pré-desportivos importantes impulsionadores do processo de ensino-aprendizagem (OLIVEIRA et al., 2015).

De acordo com Brazuna e Castro (2001), o ambiente esportivo permite aos atletas criarem um senso de responsabilidade coletiva. Aqueles com deficiência aprendem a ajudar seus companheiros, motivando-os a superarem as dificuldades e a baixa autoestima. Desse modo, se desenvolvem coletivamente, desafiando suas próprias metas e alcançando seus objetivos.

É muito comum a prática de modalidades já conhecidas de forma adaptada para que pessoas com deficiência estejam aptas a praticá-las. O IFSULDEMINAS - Campus Muzambinho desenvolve o Projeto de Educação Física Adaptada (Proefa) na região sul/sudoeste do estado de Minas Gerais, onde pessoas com deficiências mais severas praticam atividades desportivas de bocha paralímpica, como mostra a figura 1.
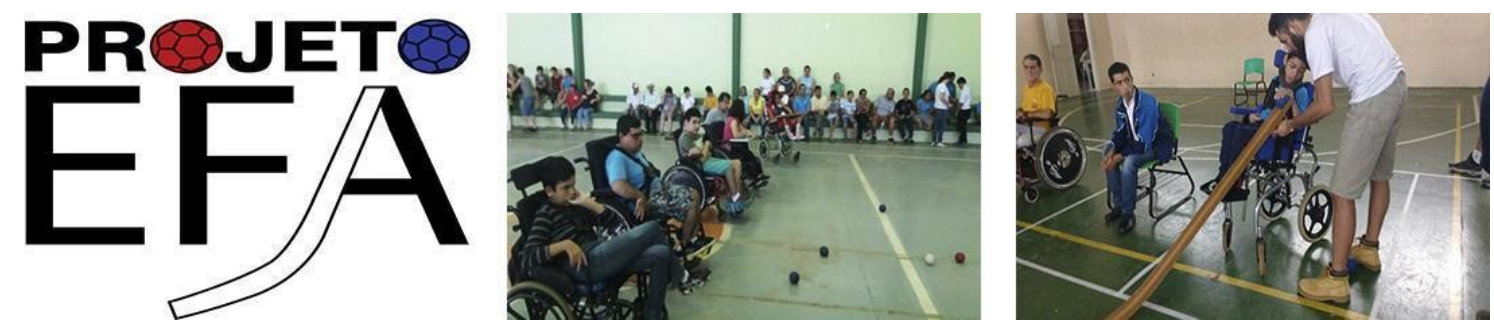

Figura 1. Projeto de educação física adaptada

A bocha é um jogo competitivo que pode ser jogado individualmente, em duplas ou em equipes. Consiste em seis bolas azuis, seis vermelhas e uma branca denominada "Jack". O objetivo é lançar as bolas coloridas o mais próximo da branca. O competidor que começar a partida fica com as bolas vermelhas, seu adversário com as azuis, ao final vence quem tiver mais bolas próximas da Jack (SANTOS, 2008 apud. OLIVEIRA et al., 2015, p. 01).

Diante dos fatores que limitam a prática de atividades desportivas, tais como a carência de educação por meio das Tecnologias da Informação e Comunicação (TICs) e a exclusão digital e social, este artigo descreve uma pesquisa que teve como objetivo efetuar uma análise sobre a influência de jogos digitais no desempenho das atividades desportivas de bocha paralímpica, a fim de proporcionar aprendizagem por meio das TICs, inclusão social e digital. Para isso, foi conduzido um estudo de caso abrangendo cinco alunos da Associação de Pais e Amigos dos Excepcionais (APAE) de Muzambinho - MG, com atividades desportivas de bocha paralímpica e atividades de uso de jogo digital de bocha. 
Buscou-se não somente o acesso às TICs, mas também que os alunos aprendessem a manuseá-las, promovendo a inclusão digital. Esforços para ampliar a inclusão digital têm crescido, mas a população não tem acompanhado o crescimento e, assim, o que era para facilitar e maximizar o tempo pode causar exclusão. Segundo Ribeiro (2007), a inclusão digital é um processo que leva o indivíduo à aprendizagem no uso das TICs, e ainda constitui uma questão de ética que oferece oportunidade a todos, fazendo a diferença em nossas vidas e para a comunidade na qual estamos inseridos. Ainda nesse contexto, Martendal e Lago (2015) frisam que a inclusão digital não se trata apenas de promover acesso às TICs, mas também proporcionar que os indivíduos nelas incluídos aproveitem ao máximo seu pensamento crítico e intelectual, podendo aplica-lo em seu contexto social.

Nessa perspectiva, professores podem utilizar essas ferramentas para ampliar conhecimentos em um ambiente escolar, facilitando a comunicação entre aluno e professor, melhorando a compreensão do que é fundamental a ser transmitido. Pereira e Silva (2013) afirmam que novas tecnologias que surgem devem ser acompanhadas não só como forma de conhecimento, mas também como fonte enriquecedora de um trabalho em um ambiente institucional.

O artigo está organizado da seguinte forma: na seção 2 segue a metodologia aplicada, na seção 3 os resultados obtidos e na seção 4 a conclusão dos resultados e trabalhos futuros.

\section{Metodologia}

O estudo de caso sobre o uso do jogo digital de bocha por pessoas com deficiência teve como objetivo verificar se esse método pode influenciar as atividades desportivas de bocha paralímpica em quadra.

Por meio de uma pesquisa aplicada, optou-se por selecionar cinco alunos da APAE de Muzambinho - MG, sendo três com paralisia cerebral, um com hidrocefalia e outro com lesão medular. Apesar do jogo de bocha paralímpica ter sido destinado a quem tem deficiência severa, decidiu-se também escolher esses outros dois alunos devido à falta de atividade desportiva para a inclusão social dos mesmos. Os responsáveis pelos discentes assinaram o Termo de Consentimento Livre e Esclarecido, concordando com a participação dos mesmos na pesquisa.

O período de aplicações e coleta de dados ocorreu de março até maio de 2018 e foi dividido em quatro etapas. A figura 2 apresenta um resumo das principais atividades conduzidas: (i) planejamento e escolha do jogo digital de bocha; (ii) teste inicial em quadra (pré-teste, avaliação diagnóstica); (iii) aulas semanais no laboratório de informática (intervenção); e (iv) teste final em quadra (pós-teste). 
VII Congresso Brasileiro de Informática na Educação (CBIE 2018)

Anais do XXIV Workshop de Informática na Escola (WIE 2018)

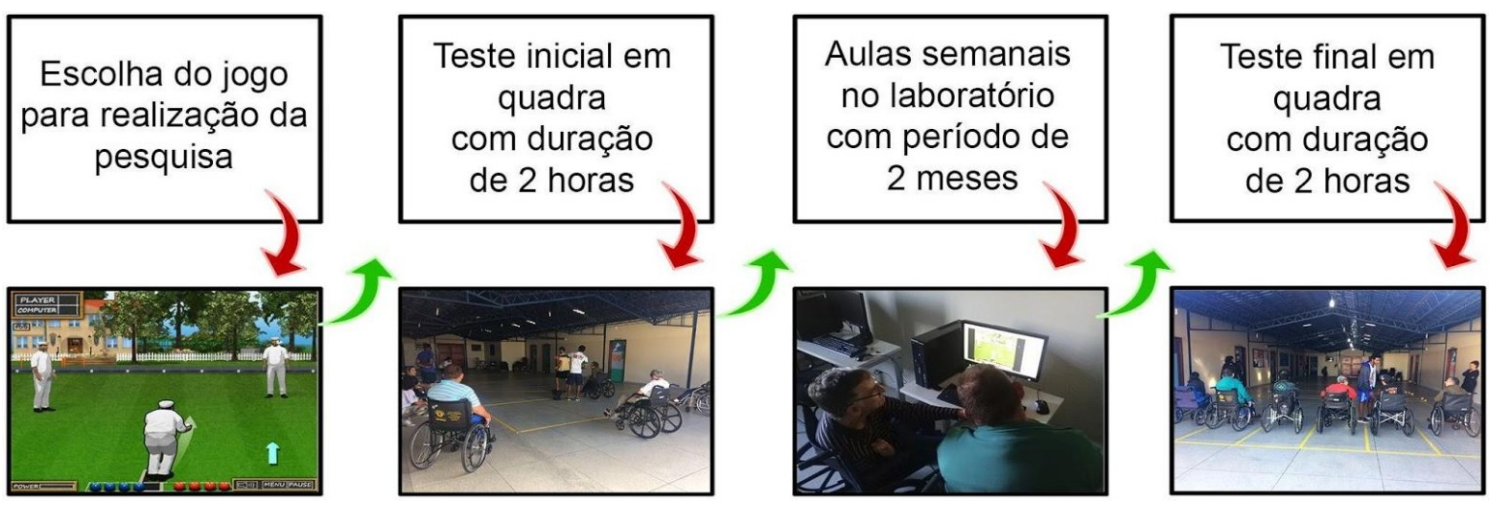

Figura 2. Etapas realizadas durante a pesquisa

Inicialmente, foram pesquisados jogos digitais considerando a utilização de computadores com acesso à internet usados no decurso do projeto e o perfil dos alunos para classificação de um jogo apropriado para as suas especificidades. Foram encontrados três jogos online disponíveis, sendo O.A.P. Lawn Bowling, Virtual Curling e Bowls. Devido ao seu fácil manuseio e a suas funcionalidades importantes, tal como o controle da força e a direção do arremesso, Bowls foi o escolhido para dar continuidade à pesquisa.

$\mathrm{Na}$ segunda etapa, os participantes foram submetidos a um teste em quadra, com duração de duas horas, para averiguar a situação inicial de cada um. Observou-se a postura dentro de quadra, noções de espaço, força, táticas e arremesso, considerando como base uma escala de três metros. Observou-se, também, a ficha técnica de cada aluno, como histórico de atividades na escola, deficiência, necessidades específicas e se houve progressão ou regressão psíquica e motora nos últimos anos em que o aluno esteve no ambiente escolar.

Em seguida, os alunos prosseguiram às intervenções na sala de informática, com duas aulas semanais, durante dois meses, acompanhados por instrutores que lhes forneceram uma série de estímulos para que pensassem criticamente visando melhores jogadas, elaboração de táticas, noções de espaço e força, assim como ocorre no jogo físico. Cada aula durava, em média, duas horas. No jogo digital foi utilizado o teclado para direcionar lançamentos (setas de navegação) e executá-los (barra de espaços). Assim como no jogo físico, o jogo digital apresentava características semelhantes, como direção da jogada, força de lançamento, táticas de jogo como, por exemplo, afastar a bola do adversário da Jack, dentre outros fatores que favoreciam os estímulos e a forma de ensinoaprendizagem, para que relacionassem o ambiente virtual com a realidade.

Para a coleta de dados relacionados ao jogo digital de bocha, foi levado em consideração o círculo ao redor da Jack, que indicava o vencedor ao final de cada rodada. Foram classificadas como jogadas eficientes as bolas presentes dentro do círculo; e como jogadas não eficientes as que ficaram fora do círculo, como mostra a figura 3. 
VII Congresso Brasileiro de Informática na Educação (CBIE 2018)

Anais do XXIV Workshop de Informática na Escola (WIE 2018)

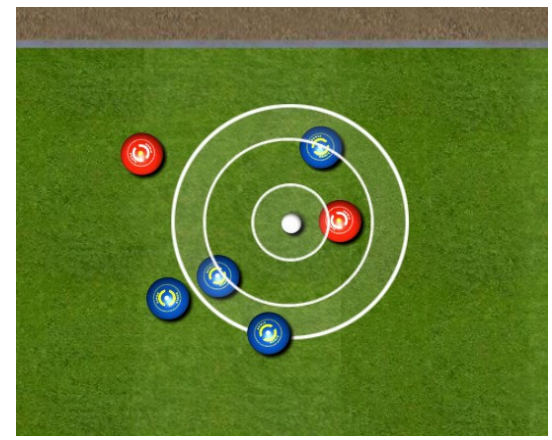

Figura 3. Bowls: círculo utilizado para classificar a eficiência das jogadas

Após a conclusão das intervenções no laboratório de informática, foi conduzida uma segunda avaliação em quadra semelhante à inicial, com os mesmos participantes e posteriormente comparada à primeira. Foram registradas as intenções de jogadas e os arremessos com distâncias pré-determinadas dos alunos. Novamente, considerou-se uma escala de 3 metros.

\section{Resultados}

As observações dos resultados iniciais foram baseadas nos dados coletados a partir das análises do desempenho dos discentes em relação à eficiência das jogadas.

Os gráficos abaixo mostram os resultados da avaliação no laboratório de informática e na quadra, onde "tv" = teste virtual, "tq"= teste em quadra. Os gráficos são de cada discentes, sendo identificados por Participante " $X$ ". Em quadra, observou-se a precisão em que as bolas eram arremessadas em lançamentos de 3 metros, no ambiente virtual foi observado a distância final entre as bolas coloridas e a Jack.

Gráfico 1. Desenvolvimento do participante "M"

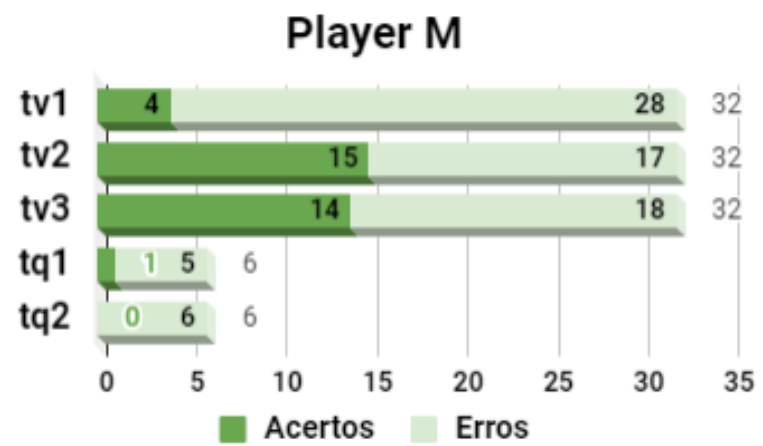

O participante "M", com paralisia cerebral, demonstrou grande melhora do primeiro teste (tv1) para o segundo (tv2). Apesar da queda de 1 acerto no terceiro (tv3), ele mostrou-se mais atencioso e compreensivo ao final dos testes. Apesar do baixo rendimento, em quadra ele fazia o uso correto do conteúdo aprendido no laboratório de informática, mas utilizava força em demasia nos lançamentos. 
VII Congresso Brasileiro de Informática na Educação (CBIE 2018)

Anais do XXIV Workshop de Informática na Escola (WIE 2018)

\section{Gráfico 2. Desenvolvimento do participante "P"}

\section{Player P}

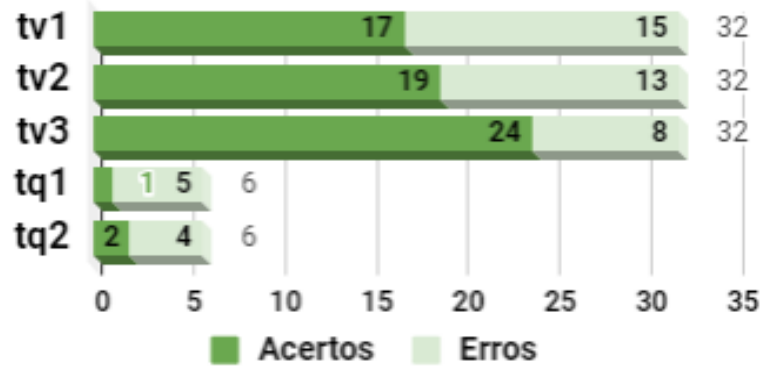

O participante "P", com paralisia cerebral, apresentou grande melhora em todos os testes feitos no laboratório de informática, além de demonstrar grande interesse pelo jogo. Em quadra, obteve uma pequena evolução e utilizou do conteúdo aprendido no laboratório para realização de jogadas e lançamentos, além de mostrar em quadra o mesmo engajamento que tinha com o jogo digital de bocha durante as aulas de informática.

\section{Gráfico 3. Desenvolvimento do participante "A"}

\section{Player A}

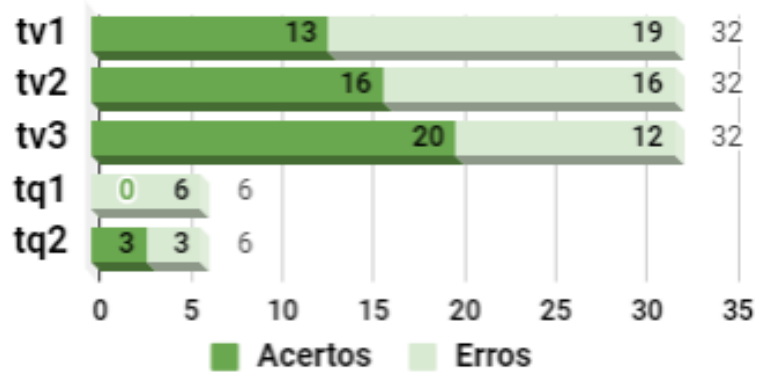

O participante "A", com hidrocefalia e distrofia progressiva, melhorou em todos os casos observados em sala. Demonstrava interesse pelo jogo, principalmente o digital. Em quadra, obteve uma melhora significativa: direcionava corretamente a bola para os lançamentos e fazia o uso de táticas aprendidas em sala. Mas, por falta de força física, não conseguia completar lançamentos em longa distância.

\section{Gráfico 4. Desenvolvimento do participante "D"}

\section{Player D}

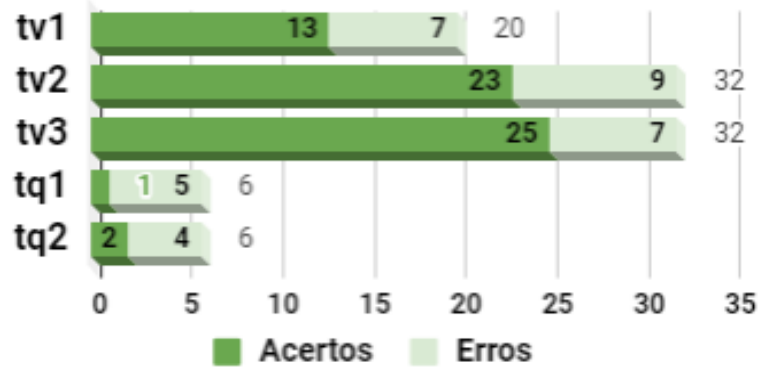


VII Congresso Brasileiro de Informática na Educação (CBIE 2018)

Anais do XXIV Workshop de Informática na Escola (WIE 2018)

O participante "D", com paralisia cerebral, melhorou de "tv1" para "tv2". Em "tv3", manteve o que estava sendo aprendido no laboratório de informática. Demonstrava grande interesse pelo jogo digital. Apesar de obter uma pequena melhora de "tq1" para "tq2", em quadra não apresentava a mesma disposição.

\section{Gráfico 5. Desenvolvimento do participante "L"}

\section{Player L}

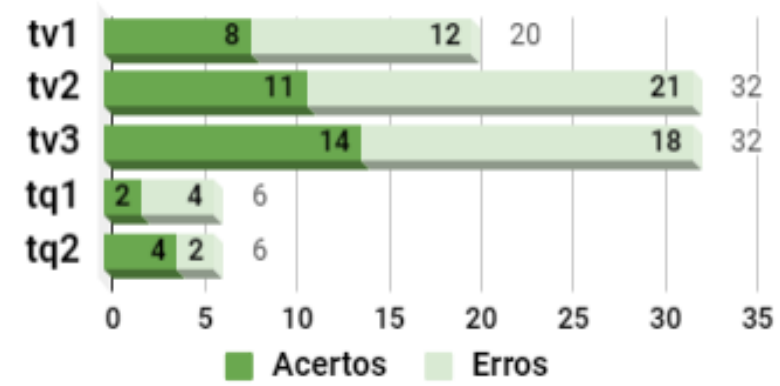

O participante "L", com lesão medular, obteve evoluções em todos os casos no ambiente de ensino. Em quadra, também obteve melhorias. Fazia uso do conteúdo aprendido mas, devido a sua condição motora, não conseguia realizar alguns lançamentos.

Pelos dados que foram analisados, de forma geral, notou-se uma melhora em todos os testes realizados com o jogo digital, além de maior desempenho da maioria dos participantes no segundo teste em quadra (tq2), em relação ao primeiro (tq1). Os indivíduos que já tinham maior empenho em quadra, observados na avaliação diagnóstica (pré-teste), também foram os mais competitivos taticamente no jogo digital.

A tabela abaixo mostra características e comportamentos notados em cada aluno durante as aulas de informática.

Tabela 1. Características e comportamentos observados durante a pesquisa

\begin{tabular}{cl}
\hline Jogador & Características observadas \\
\hline M & $\begin{array}{l}\text { Jogador M não demostrava muito interesse em acertar as jogadas mas foi participativo, } \\
\text { em quadra utilizava muita força nos lançamentos. }\end{array}$ \\
P & $\begin{array}{l}\text { Jogador P era bastante atencioso e participativo. Em quadra acertava a maioria dos } \\
\text { lançamentos. }\end{array}$ \\
& $\begin{array}{l}\text { Jogador A também apresentava interesse pelo jogo, mas devido sua condição motora } \\
\text { errava alguns lançamentos no teclado. Em quadra, por falta de força, acabava errando as } \\
\text { jogadas mesmo tendo direcionado corretamente. }\end{array}$ \\
& $\begin{array}{l}\text { Jogador D acertava a maioria dos lançamentos no ambiente virtual. Em quadra acertava } \\
\text { alguns lances mas demonstrava mais interesse pelo ambiente virtual. }\end{array}$ \\
& Jogador L tinha dificuldades em manusear o teclado no jogo digital, em quadra acertava \\
& algumas jogadas, levando em conta sua condição motora.
\end{tabular}

Um dos pontos observados durante os testes com o jogo digital foi que muitos participantes reconheciam seus erros, faziam análises das jogadas e identificavam formas de corrigir o erro para concluir com sucesso seu próximo lançamento. Entretanto, como o Bowls não é um jogo digital de bocha adaptado para atender as necessidades de pessoas 
VII Congresso Brasileiro de Informática na Educação (CBIE 2018)

Anais do XXIV Workshop de Informática na Escola (WIE 2018)

com deficiência, em meio à pesquisa foram encontradas dificuldades, tais como: não possuir a delimitação de espaço físico (quadra com as marcações), nem opção para lançamentos em linha reta da bola, dentre outras características desfavoráveis para esse contexto. Adicionalmente, por ser um jogo na web, muitas propagandas apareciam na tela, o que ocasionava a dispersão dos alunos.

\section{Conclusão}

Por meio dos resultados obtidos, concluiu-se que é importante utilizar táticas e recursos como instrumento para facilitar o ensino de bocha paralímpica. Ao observar a importância desse assunto no cenário escolar, foi possível intensificar o compromisso da escola em proporcionar a inclusão social e digital.

O jogo digital de bocha aplicado às pessoas com deficiência concede uma considerável evolução da visão de jogo, das estratégias e das coordenações empregadas no jogo de bocha adaptado para quadra. Foi observado que após os alunos terem acesso ao ensino de forma diferenciada, além de uma série de estímulos, eles se apresentaram mais competitivos e engajados no jogo físico.

Contudo, esta afirmação não pode ser generalizada, pois refere-se a um estudo de caso aplicado com apenas cinco integrantes. Os índices observados podem colaborar para pesquisas futuras contendo um jogo virtual que seja adaptado, ou para trabalhos relacionados a atividades equivalentes.

Sobre os alunos, almejamos que eles mantenham o desenvolvimento físico e habilidades motoras, desfrutando de uma vida mais saudável com a socialização e a prática de esportes, o que poderia confirmar os benefícios apontados por Bittar (op. cit.).

\section{Referências}

BITTAR, I., et al. (2013) "Efeitos de um programa de jogos pré-desportivos nos aspectos psicobiológicos de idosas", Revista Brasileira de Geriatria e Gerontologia, v. 16, n. 4, p. 713 725 .

BRASIL. Decreto n. 13.146, de 6 de jun. de 2015. "Inclusão da Pessoa com Deficiência (Estatuto da Pessoa com Deficiência)”, Brasília, DF, julho 2015.

BRAZUNA, M., CASTRO, E. (2001) "A trajetória do atleta portador de deficiência física no esporte adaptado de rendimento: uma revisão da literatura", Motriz, Revista de Educação Física - UNESP, v. 7, n. 2, p. 115-123.

MARTENDAL, F., LAGO, S. (2015) "Uma reflexão sobre a Inclusão digital como forma de transformação e capacitação dos indivíduos", I CINGEN, Conferência Internacional de Gestão de Negócios.

OLIVEIRA, A., et al. (2015) "Projeto de Extensão Universitária: Jogos Pré Desportivos Para o Ensino da Bocha Adaptada às Pessoas com Deficiências Múltiplas", ADAPTA, Revista Profissional da Sobama, v. 11, n. 1.

PEREIRA, M., SILVA, T. (2013) "O uso da tecnologia na educação na era digital”, Revista Saberes em Rede CEFAPRO de Cuiabá-MT.

RIBEIRO, M. (2007) “Inclusão digital e cidadania”, Artigo. UNESP, São Paulo.

SOBRAL, F., et al. (2017) "A Utilização de Role Playing Games Digitais como Ferramenta Complementar no Processo de Aprendizagem de Crianças Deficientes Visuais", Universidade Federal do Paraná. 